\title{
MUDANÇAS CLIMÁTICAS GLOBAIS E AÇÕES LOCAIS: A CONTRIBUIÇÃO DO PROGRAMA ARBORETUM PARA OS MARCOS REGULATÓRIOS DE FLORESTAS E CLIMA
}

\author{
AUTOR: STEFANIE DA HORA SILVA \\ CO-AUTOR: FREDERICO MONTEIRO NEVES \\ CO-AUTOR/ORIENTADOR: GUINEVERRE ALVAREZ MACHADO DE MELO GOMES
}

\begin{abstract}
Resumo: A crise climática foi intensificada ao longo do tempo em decorrência das atividades humanas e seus efeitos já são sentidos por muitos países. O enfrentamento global da crise climática tem sido marcado por planos e tratados que influenciam na construção dos dispositivos legais nacionais, com adoção de medidas de mitigação de gases de efeito estufa (GEE) e da adaptação aos efeitos adversos das mudanças do clima. $O$ desafio de aliar as diretrizes internacionais às ações locais ainda persiste. No Brasil, cujo maior vetor de emissões de GEE é o uso da terra, especialmente o desmatamento, experiências locais/regionais de conservação e restauração florestal podem ser campo profícuo para melhor refletir sobre estes crescentes desafios. Este trabalho pretendeu identificar de quais formas as ações do Programa Arboretum contribuem para os marcos regulatórios de mudanças climáticas e florestas no plano internacional, nacional e estadual baiano. Trata-se de uma pesquisa qualitativa e descritiva, em que foram analisados dados secundários e primários (observação, entrevistas e grupos focais) do Programa Arboretum, posteriormente confrontados com as principais normas internacionais, nacionais e baianas de mudança do clima e florestas. Os resultados apontam para importante contribuição do Programa nos três níveis normativos, a exemplo do Protocolo de Kyoto, Acordo de Paris, iNDC brasileira, PNMC, Política Estadual de Pagamentos por Serviços Ambientais da Bahia, entre outros.
\end{abstract}

Palavras-chave: Mudança do climática, Programa Arboretum, Mata Atlântica. 